УДК 632.954:[633.15+633.853.492+633.63]

ОСОБЕННОСТЬ АНТИДОТНОГО ДЕЙСТВИЯ

ИЗОКСАДИФЕН-ЭТИЛА В СОСТАВЕ ПРОТРАВИТЕЛЕЙ СЕМЯН СЕЛЬСКОХОЗЯЙСТВЕННЫХ КУЛЬТУР

${ }^{1}$ Спиридонов Ю.Я., ${ }^{1}$ Чичварина О.А., ${ }^{2}$ Сиган А.Л., ${ }^{2}$ Чкаников Н.Д., ${ }^{2}$ Халиков С.С.

${ }^{\prime}$ ФГБНУ «Всероссийский научно-исследовательский институт фитопатологии»,

p.n. Большие Вяземы, Московская область, e-mail: spiridonov@vniif.ru;

${ }^{2}$ ФГБУН «Институт элементоорганических соединений им. А.Н. Несмеянова»

Российской академии наук, Москва, е-mail: salavatkhalikov@таil.ru

Известно, что ежегодные мировые потери важнейших сельскохозяйственных культур из-за отсутствия контроля сорняков составили бы приблизительно 10-15\% от достижимого урожая. Поэтому применение гербицидов для борьбы с сорняками является одним из приоритетных направлений в развитии сельскохозяйственного производства для получения высоких урожаев. Однако неконтролируемое использование гербицидов привело к засорению почв их остатками и другим экологическим последствиям (эрозия и засоление почв из-за обильного использования ирригационных систем, истощение водоносных горизонтов, потеря лесных и пр.). Ежегодный ущерб урожаю таких культур, как сахарная свекла, подсолнечник, картофель, соя и рапс, отличающихся особенно высокой чувствительностью к остаткам некоторых действующих веществ сульфонилмочевин и имидазолинонов, достигает $20 \%$. Для защиты всходов культурных растений от почвенных остатков гербицидов класса сульфонилмочевин предложено использовать антидот - изоксадифен-этил (ИДЭ). Этот антидот был ранее рекомендован компанией Bayer Crop Science для снятия фитотоксического действия послевсходовых гербицидов йодосульфурон-метил-натрий и форамсульфурон при их совместном применении на зерновых культурах путем опрыскивания в период вегетации. Авторами настоящей статьи впервые предложено использовать ИДЭ в составе протравителя для снятия фитотоксического действия гербицида Зингер, СП (60\% метсульфурон-метил) при его остатке в почве от 1 до 2,5 г/га. Показана возможность использования ИДЭ в составе рецептур ранее разработанных суспензионных и эмульсионных форм протравителя на кукурузе, рапсе и сахарной свекле. Подтверждено, что суспензионная форма протравителя с добавлением ИДЭ более эффективна, чем эмульсионная форма. Комплексный протравитель, содержащий ИДЭ в норме от 50 до 200 г/л, снимал токсическое действие гербицида Зингер от 27 до $50 \%$ на кукурузе. Увеличение нормы расхода ИДЭ с 100 до 200 г/л не приводило к увеличению антидотного действия. Выявлены стимулирующие в сравнении с контролем (вода) свойства ИДЭ. Испытания суспензионных форм протравителя с ИДЭ на семенах гибрида сахарной свеклы Кариока в норме 10-100 г/л показали, что эти композиции не обладают антидотным действием, но все эти композиции обладают высокой стимулирующей активностью (от 51,1 до $100 \%$ ) на почвах, не обработанных гербицидом.

Ключевые слова: гербициды, остатки сульфонилмочевин, антидоты, снятие токсического действия, кукуруза, рапс, сахарная свекла

\title{
SPECIAL FEATURES OF ANTIDOTE ACTIVITY OF ISOXADIFENE-ETHYL IN COMPOSITION OF PROTECTANTS OF SEEDS OF AGRICULTURAL CROPS
}

${ }^{1}$ Spiridonov Yu.Ya., ${ }^{1}$ Chichvarina O.A., ${ }^{2}$ Sigan A.L., ${ }^{2}$ Chkanikov N.D., ${ }^{2}$ Khalikov S.S. ${ }^{1}$ All-Russian Research Institute of Phytopathology, Bolshie Vyazemy, Moscow region, e-mail: spiridonov@vniif.ru;

${ }^{2}$ A.N. Nesmeyanov Institute of Organoelement Compounds, Russian Academy of Sciences, Moscow,e-mail: salavatkhalikov@mail.ru

It is known that the annual world losses of important crops due to lack of control of weeds can equal about $10-15 \%$ of the achievable yield. Therefore, the use of herbicides for control of weeds is one of the priori directions in development of agricultural production for obtaining high yields. However, uncontrolled use of herbicides led to clogging of soils with their residues and other environmental consequences (erosion and salinization of soils due to abundant use of irrigation systems, depletion of aquifers, loss of forest, etc.). Annual damage to crops such as sugar beets, sunflower, potatoes, soybeans and rapeseeds, which are especially sensitive to the residues of certain active substances of sulfonylureas and imidazolinones, reaches $20 \%$. To protect the emergence of cultivated plants from soil residues of herbicides of the sulfonylurea class, it has been suggested to use antidote isoxadifen-ethyl (IDE). This antidote was previously recommended by Bayer CropScience to remove the phytotoxic effect of post-emergence herbicides iodosulfuron-methyl-sodium and foramsulfuron when combined in cereal crops by spraying during the growing season. The authors of the present article suggested for the first time to use the IDE in composition of the protectant to remove the phytotoxic effect of the herbicide Singer, SP (60\% methsulfuron-methyl) with its residue in the soil from 1 to $2.5 \mathrm{~g}$ / ha. The possibility of using the IDE in formulation of the previously developed suspension and emulsion forms of protectant in maize, rapeseed and sugar beet is shown. It was confirmed that suspension form of the protectant with the addition of IDE is more effective than the emulsion form. Complex etchant, the content of IDE in the normal range from 50 to $200 \mathrm{~g} / 1$, removed the toxic effect of herbicide Singer from 27 to $50 \%$ on corn. The increase in the rate of consumption of IDE from 100 to $200 \mathrm{~g} / 1$ did not lead to an increase in the antidote effect. The properties of IDE stimulation in comparison with the control (water) have been revealed. Tests of the suspension forms of the protectant with IDE on the seeds of sugar beet grade Karioka in the norm of 10-100 g / 1 showed that these compositions do not have antidote activity, but all these compositions have high stimulating activity (from 51.1 to $100 \%$ ) in soils, not treated with herbicide.

Keywords: herbicides, residues of sulfonylureas, antidotes, removal of toxic effect, corn, rapeseed, sugar beet 
Борьба с сорняками, оставаясь одной из приоритетных задач современного сельскохозяйственного производства, приводит к засоренности почв остатками гербицидов, которые не только создают экологические проблемы для ближайшего будущего, но и негативно воздействуют на культуру, посев которой запланирован на следующий год. Это особенно актуально в случае посева корнеплодов (сахарная свекла, картофель и пр.) [1]. Для решения вопросов защиты чувствительной культуры от почвенных остатков гербицидов ряда сульфонилмочевин еще в конце прошлого века был предложен ряд веществ, в том числе оригинальных, выполняющих роль антидотов [2]. Однако это направление работ не имело продолжения в силу ряда объективных и субъективных причин (остановка работы химических заводов, прекращение производства собственных пестицидов, антидотов и пр.). В последние годы западными фирмами стало активно развиваться направление совместного использования гербицидов с антидотами для защиты культурного растения в период вегетации $[2,3]$.

Целью настоящей работы было установление возможности использования так называемого антидота вегетационного периода (изоксадифен-этила [4]) при включении его в состав протравителей, используемых для обработки посевного материала изучаемых культур, чтобы защитить их от остатков гербицида в почве.

Для выполнения поставленной цели был выполнен ряд задач:

1) подбор рецептур препаративных форм на основе изучения физико-химических свойств ИДЭ, разработка оптимальных составов многокомпонентных протравителей, оценка их технологических параметров и выявление препаратов для проведения биологических испытаний;

2) изучение антидотного действия предложенных по п. 1 протравителей для предпосевной обработки семян кукурузы, рапса и сахарной свеклы.

\section{Материалы и методы исследования}

Исходное соединение (ИДЭ, этиловый эфир- 4,5-дигидро-5,5-дифенил-изоксазол3-карбоновой кислоты) было получено по методике [5] реакцией конденсации 1,1-дифенилэтилена с этиловым эфиром нитроуксусной кислоты в присутствии 1,4-диазабицикло[2.2.2]октана в качестве катализатора.

Чистота продукта контролировалась методом ВЭЖХ (колонка Hypersil Elite C18,
150 x 4,6 мм, элюент $\mathrm{CH}_{3} \mathrm{CN}-$ вода $=50: 50$, расход 1 мл/мин, температура термостата колонки $30^{\circ} \mathrm{C}$, УФ $\left.220 \mathrm{нм}\right)$.<smiles>CCOC(=O)C1=NOC(c2ccccc2)(c2ccccc2)C1</smiles>

Для изучения антидотного действия ИДЭ в составе протравителя была использована следующая схема исследования:

1. Сначала индивидуально антидот ИДЭ готовили в виде суспензионных и эмульсионных форм. Количество антидота ИДЭ в них варьировалось от 1 до 100 г/л.

2. Антидотную активность суспензионной и эмульсионной форм ИДЭ определяли после обработки ими семян гибрида кукурузы Астерин и семян сорта рапса ярового Мерано в норме от 1 до 100 г/т семян.

3. Комплексные антидотные протравители (с включением фунгицидов тебуконазола /ТБК/ и тиурама /ТМТД/) готовили в виде суспензионного концентрата с содержанием ИДЭ 50, 100 и 200 г/л.

4. Антидотную активность комплексных препаратов (ТБК, ТМТД, ИДЭ) определяли после обработки ими семян гибрида кукурузы Краснодарский 291 АМВ в норме 50-200 г/л, семян сорта рапса ярового Ратник в норме 10-100 г/л и семян гибрида сахарной свеклы Кариока в норме 10-100 г/л.

Препараты готовились по методике, описанной ранее в работе [6]. При этом были получены суспензионные и эмульсионные препараты на основе ИДЭ, которые испытаны в ЛИК (камеры фирмы «Фетч», ФРГ) в виде рабочих растворов (РР) с нормами 1, 10 и 100 г/л. Изучение антидотного действия препаративных форм ИДЭ проводили согласно методике, описанной в работе [6]. Обработку почвы гербицидом Зингер, СП (60\% метсульфурон-метил) проводили в дозе 0,$5 ; 1,0$ и 2,5 г/га.

\section{Результаты исследования и их обсуждение}

Как известно, МайсТер является гербицидом системного действия и, перемещаясь по всему сорному растению с восходящим и нисходящим током питательных веществ, он поражает биохимическую мишень - фермент ацетолактатсинтетазу, участвующий в цепи биосинтеза амино- 
кислот, нарушает процессы синтеза белков, что вызывает прекращение деления клеток в меристемных тканях [4]. Препарат высокоэффективен против однолетних и многолетних злаковых и двудольных сорняков в посевах кукурузы. Благодаря содержанию антидота (ИДЭ) обеспечивается высокая селективность к обрабатываемой культуре, и поэтому препарат хорошо переносится большинством зарегистрированных сортов и гибридов кукурузы в рекомендованных нормах внесения.

В отличие от рекомендаций компании Bayer Crop Science по применению препарата МайсТер, нами рассматривалась возможность использования ИДЭ в составе протравителя для снятия токсического действия почвенных остатков гербицида из производных сульфонилмочевины на всходы культурного растения (кукуруза, рапс). Гербицид Зингер, СП в дозе 8-10 г/га широко применяется в борьбе с широколиственными сорняками в посевах зерновых колосовых культур практически во всех регионах РФ. Существенным недостатком данного гербицида является длительное (от 12 до 18 месяцев) сохранение его фитотоксических остатков в почве, которые приносят существенный ущерб урожаю последующих в севообороте кукурузы и рапса. Полученные результаты представлены в табл. 1.

Анализ полученных результатов показал, что:

1) на изучаемых культурах суспензионная форма ИДЭ более эффективна, чем эмульсионная, что подтверждено следующими данными:

- при норме 100 г/л ИДЭ в суспензии проявил наибольшую активность на кукурузе (снижение массы тест-растений кукурузы составило $37 \%$ );

- наибольший антидотный эффект на рапсе наблюдался при использовании суспензионной формы в норме 10 г/л (снижение массы тест-растений рапса составило 58,8\%).

Антидотная активность суспензионных и эмульсионных форм ИДЭ

\begin{tabular}{|c|c|c|c|c|}
\hline Вариант & $\begin{array}{c}\text { Норма применения } \\
\text { антидота ИДЭ, } \\
\text { г/т семян }\end{array}$ & $\begin{array}{l}\text { Доза герби- } \\
\text { цида Зингер, } \\
\text { СП, г/га }\end{array}$ & $\begin{array}{c}\text { Надземная масса } \\
\text { тест-растений (cp. } \\
\text { по повторностям), г }\end{array}$ & $\begin{array}{c}\text { Снижение массы тест- } \\
\text { растений, \% к безгерби- } \\
\text { цидному контролю }\end{array}$ \\
\hline \multicolumn{5}{|c|}{ Кукуруза } \\
\hline \multirow{3}{*}{$\begin{array}{l}\text { Эмульсионная } \\
\text { форма }\end{array}$} & 1 & \multirow[t]{7}{*}{2,5} & 1,8 & 66,7 \\
\hline & 10 & & 3,0 & 44,4 \\
\hline & 100 & & 1,8 & 66,7 \\
\hline \multirow{3}{*}{$\begin{array}{c}\text { Суспензионная } \\
\text { форма }\end{array}$} & 1 & & 1,4 & 74,1 \\
\hline & 10 & & 2,3 & 57,4 \\
\hline & 100 & & 3,4 & 37,0 \\
\hline $\begin{array}{c}\text { Контроль } \\
\text { гербицидный } \\
\text { (Зингер, СП) }\end{array}$ & - & & 1,8 & 66,7 \\
\hline $\begin{array}{l}\text { Контроль безгер- } \\
\text { бицидный (вода) }\end{array}$ & - & - & 5,4 & 0 \\
\hline $\mathrm{HCP}_{05}$ & & & 0,6 & \\
\hline \multicolumn{5}{|c|}{ Рапс } \\
\hline \multirow{3}{*}{$\begin{array}{c}\text { Эмульсионная } \\
\text { форма }\end{array}$} & 1 & \multirow[t]{7}{*}{1,0} & 0,6 & 64,7 \\
\hline & 10 & & 0,3 & 82,4 \\
\hline & 100 & & 0,6 & 64,7 \\
\hline \multirow{3}{*}{$\begin{array}{c}\text { Суспензионная } \\
\text { форма }\end{array}$} & 1 & & 0,5 & 70,6 \\
\hline & 10 & & 0,7 & 58,8 \\
\hline & 100 & & 0,2 & 88,2 \\
\hline $\begin{array}{c}\text { Контроль } \\
\text { гербицидный } \\
\text { (Зингер, СП) }\end{array}$ & - & & 0,4 & 76,5 \\
\hline $\begin{array}{l}\text { Контроль безгер- } \\
\text { бицидный (вода) }\end{array}$ & - & - & 1,7 & 0 \\
\hline $\mathrm{HCP}_{05}$ & & & 0,6 & \\
\hline
\end{tabular}


Таблица 2

Антидотная активность комплексных протравителей с ИДЭ при обработке семян гибрида кукурузы Краснодарский 291 АМВ

\begin{tabular}{|c|c|c|c|c|}
\hline $\begin{array}{c}\text { Состав протравителя } \\
\text { (норма расхода ФМ-4, г/л) }\end{array}$ & $\begin{array}{c}\text { Доза герби- } \\
\text { цида Зингер, } \\
\text { СП, г/га }\end{array}$ & $\begin{array}{c}\text { Надземная мас- } \\
\text { са тест-растений } \\
\text { (ср. по повтор- } \\
\text { ностям), г }\end{array}$ & $\begin{array}{c}\text { Снижение } \\
\text { массы тест- } \\
\text { растений, \% } \\
\text { к безгербицид- } \\
\text { ному контролю }\end{array}$ & $\begin{array}{l}\text { «Антидотный» } \\
\text { эффект, \% } \\
\text { к гербицидно- } \\
\text { му контролю } \\
\text { (Зингер, СП) }\end{array}$ \\
\hline \multirow[t]{2}{*}{ Композиция I (50) } & - & 10,0 & $-14,9$ & - \\
\hline & 2,5 & 5,6 & 35,6 & $-27,3$ \\
\hline \multirow[t]{2}{*}{ Композиция II (100) } & - & 10,9 & $-25,3$ & - \\
\hline & 2,5 & 6,6 & 24,1 & $-50,0$ \\
\hline \multirow[t]{2}{*}{ Композиция III (200) } & - & 9,3 & $-6,9$ & - \\
\hline & 2,5 & 6,3 & 27,6 & $-43,2$ \\
\hline \multirow[t]{2}{*}{ Композиция 0 - эталон } & - & 10,6 & $-21,8$ & - \\
\hline & 2,5 & 5,4 & 37,9 & $-22,7$ \\
\hline Контроль гербицидный (Зингер, СП) & 2,5 & 4,4 & 49,4 & 0 \\
\hline Контроль безгербицидный (вода) & - & 8,7 & 0 & - \\
\hline $\mathrm{HCP}_{05}$ & & 1,4 & & \\
\hline
\end{tabular}

П р и м е ч а н и е . Отрицательные значения - стимуляция роста растений.

С учетом этих данных нами готовились комплексные протравители в виде суспензионных концентратов с применением таких формообразующих компонентов, как пропиленгликоль (ПЭГ-400), натриевая соль карбоксиметилцеллюлозы (Na-КМЦ), эмульгатор-пленкообразователь (Тренд-90) и следующих действующих веществ:

- фунгицида ТБК - 25,0 г/л;

- инсектофунгицида ТМТД - 200,0 г/л;

- антидота ИДЭ - 10, 25, 50, 100 и 200 г/л;

Препараты представляли собой суспензионные концентраты, образующие стабильные рабочие растворы, используемые для протравливания семян гибрида кукурузы Краснодарский 291 АMB, семян сорта рапса ярового Ратник и семян гибрида сахарной свеклы Кариока. По результатам испытаний на семенах кукурузы (табл. 2) установлено, что комплексный протравитель, содержащий ИДЭ в норме от 50 до 200 г/л, снимал фитотоксическое действие гербицида Зингер (при его остатке в почве в 2,5 г/га) от 27 до $50 \%$. Также обнаружено, что увеличение нормы расхода ИДЭ с 100 до 200 г/л не приводило к усилению антидотного действия. Кроме того, выявлены стимулирующие в сравнении с контролем (вода) свойства ИДЭ. Наибольший стимулирующий эффект наблюдался в композиции II, содержащей 100 г/л антидота ИДЭ, выражающийся в 25,3\% (по сравнению с контролем - вода) и 3,5\% (по сравнению со стандартом - комплексный протравитель без ИДЭ). Следовательно, оптимальной нормой применения ИДЭ в комплексном протравителе нами определено значение 100 г/л.

Аналогично были испытаны суспензионные протравители с содержанием ИДЭ в норме 10-100 г/л на семенах рапса ярового сорта Ратник. Результаты испытаний (табл. 3) показали, что лишь композиция IV c нормой 100 г/л показала антидотный эффект $(54,5 \%)$ по сравнению с гербицидным контролем, а все остальные композиции с нормой ИДЭ от 10 до 50 г/л обладали стимулирующим действием на почвах, не обработанных гербицидом. Стимулирующий эффект проявлялся от 11,1 до $44,4 \%$.

Испытания суспензионных форм протравителя с ИДЭ на семенах гибрида сахарной свеклы Кариока в норме 10-100 г/л показали, что композиции с ИДЭ не обладают антидотным действием (табл. 4). Однако все композиции обладают высокой стимулирующей активностью на почвах, не обработанных гербицидом - от 51,1 до $100 \%$.

\section{Выводы}

Показана возможность применения известного антидота ИДЭ в составе комплексного протравителя при предпосевной обработке семян кукурузы, рапса и сахарной свеклы для снятия токсического действия 
почвенных остатков гербицида метсульфурон-метила. При обработке протравителем, содержащим ИДЭ в норме от 50 до 200 г/л, семян гибрида кукурузы Краснодарский 291 АМВ обнаружено снятие фитотоксического действия гербицида Зингер (при его остатке в почве в 2,5 г/га) от 27 до $50 \%$. Обработка же семян рапса ярового сорта Ратник протравителем с ИДЭ в норме 100 г/л обнаружен 54\%-ный антидотный эффект. Антидотных свойств этих композиций не обнаружено при обработке ими семян гибрида сахарной свеклы Кариока. Все приготовленные композиции с включением в свой состав ИДЭ обладали высокими показателями стимулирующей активности при обработке ими семян всех видов изученных культур.

Антидотная активность комплексных протравителей с ИДЭ при обработке семян рапса ярового сорта Ратник

\begin{tabular}{|l|c|c|c|}
\hline \multirow{2}{*}{$\begin{array}{c}\text { Вариант композиции } \\
\text { содержание ИДЭ, г/л) }\end{array}$} & $\begin{array}{c}\text { Доза герби- } \\
\text { цида Зингер, } \\
\text { СП, г/га }\end{array}$ & $\begin{array}{c}\text { Надземная масса } \\
\text { тест-растений } \\
\text { (ср. по повторностям), г }\end{array}$ & $\begin{array}{c}\text { Снижение массы тест- } \\
\text { растений,\% к безгерби- } \\
\text { цидному контролю }\end{array}$ \\
\hline \multirow{2}{*}{ Композиция I (10) } & - & 3,3 & $-22,2$ \\
\hline \multirow{2}{*}{ Композиция II (25) } & 0,5 & 1,1 & 59,3 \\
\cline { 2 - 4 } & - & 3,9 & $-44,4$ \\
\hline \multirow{2}{*}{ Композиция III (50) } & - & 1,1 & 59,3 \\
\hline Композиция IV (100) & 0,5 & 3,3 & $-22,2$ \\
\cline { 2 - 4 } & 0,5 & 1,6 & 40,7 \\
\hline Композиция 0 - эталон & - & 3,3 & $-22,2$ \\
\cline { 2 - 4 } & 0,5 & 2,1 & $-14,8$ \\
\hline Контроль гербицидный (Зингер, СП) & 0,5 & 3,1 & 55,6 \\
\hline Контроль безгербицидный (вода) & - & 1,2 & 40,7 \\
\hline НСР & & 2,6 & 0 \\
\hline
\end{tabular}

П р и м еч а н и е . Отрицательные значения - стимуляция роста растений.

Антидотная активность комплексных протравителей с ИДЭ

Таблица 4 при обработке семян гибрида сахарной свеклы Кариока

\begin{tabular}{|l|c|c|c|}
\hline \multirow{2}{*}{$\begin{array}{c}\text { Вариант композиции } \\
\text { (содержание ИДЭ, г/л) }\end{array}$} & $\begin{array}{c}\text { Доза герби- } \\
\text { цида Зингер, } \\
\text { СП, г/га }\end{array}$ & $\begin{array}{c}\text { Надземная масса } \\
\text { тест-растений } \\
\text { (ср. по повторностям), г }\end{array}$ & $\begin{array}{c}\text { Снижение массы тест- } \\
\text { растений, \% к безгерби- } \\
\text { цидному контролю }\end{array}$ \\
\hline Композиция I (10) & - & 7,6 & $-68,9$ \\
\hline \multirow{2}{*}{ Композиция II (25) } & 0,5 & 0,6 & 86,7 \\
\cline { 2 - 4 } & - & 9,0 & $-100,0$ \\
\hline Композиция III (50) & - & 0,7 & 84,4 \\
\hline \multirow{2}{*}{ Композиция IV (100) } & 0,5 & 6,2 & $-37,8$ \\
\hline \multirow{2}{*}{ Композиция 0-эталон } & - & 0,7 & 84,4 \\
\hline Контроль гербицидный (Зингер, СП) & 0,5 & 6,8 & $-51,1$ \\
\hline Контроль безгербицидный (вода) & - & 0,7 & 84,4 \\
\hline НСР & 0,5 & 7,1 & $-57,8$ \\
\hline 05 & & 0,7 & 84,4 \\
\hline
\end{tabular}

П р и м е ч а н и . Отрицательные значения - стимуляция роста растений. 


\section{Список литературы / References}

1. Спиридонов Ю.Я., Хохлов П.С., Шестаков В.Г. Антидоты гербицидов // Агрохимия. 2009. № 4. С. 81-91.

Spiridonov Yu.Ya., Khokhlov P.S., Shestakov V.G. Antidotes of herbicides // Agricultural Chemistry. 2009. № 4. P. 81-91 (in Russian).

2. Яблонская Е.К., Котляров В.В., Федулов Ю.П. Антидоты гербицидов сельскохозяйственных культур (Обзор) Научный журнал КубГАУ. 2013. № 94 (10). URL: http:/ ej.kubagro.ru/2013/10/pdf/33.pdf (дата обращения: 06.09.2018)

Yablonskay H.K. The Herbicides Antidotes of Agricultura Crops (Overview) // URL: http://ej.kubagro.ru/2013/10/pdf/33. pdf (data obrashheniya: 06.09.2018) (in Russian)

3. Государственный каталог пестицидов и агрохимикатов, разрешенных к применению на территории Российской Федерации. М., 2015735 с.

The state catalog of the pesticides and agrochemicals allowed for use in the territory of the Russian Federation. M. 2015. 735 p. (in Russian).
4. Миханькова Т.А., Кириленко Е.И., Редюк С.И. Новый гербицид майстер для прополки кукурузы // Защита и карантин растений. 2010. № 2. С. 38 .

Makhankova T.A., Kirilenko E.I., Redyuk S.I. A New Herbicide Maister for Corn Weeding // Zashhita i karantin rastenij. 2010. № 2. P. 38 (in Russian).

5. Cremonesi G., Croce P.D., Fontana F., Fiorelli C., La Rosa C. Stereoselective synthesis of $\beta, \varepsilon$-dihydroxy- $\alpha$-amino acids by ring opening of 4,5-dihydroisoxazolyl derivatives, Tetrahedron: Asymmetry. 2008. № 19. P. 2850-2855.

6. Халиков С.С., Чкаников Н.Д., Спиридонов Ю.Я., Глинушкин А.П. Новый препарат для предпосевной обработки семян с комплексной защитой от болезней и остатков гербицидов в почве // Агрохимия. 2016. № 6. С. 39-45.

Khalikov S.S., Chkanikov N.D., Spiridonov J.Y., Glinushkin A.P. The New Drug for Pre-Treatment of Seeds with Comprehensive Protection against Diseases and Herbicide Residues in Soil // Agricultural Chemistry. 2016. № 6. P. 39-45 (in Russian). 